\title{
The Effect of High-Energy Ball Milling Conditions on Microstructure and Hydrogen Desorption Properties of Magnesium Hydride and Single-Walled Carbon Nanotubes
}

\author{
Viktor N. Kudiyarov, Roman R. Elman * and Nikita E. Kurdyumov \\ Division for Experimental Physics, School of Nuclear Science \& Engineering, National Research Tomsk \\ Polytechnic University, 634050 Tomsk, Russia; kudiyarov@tpu.ru (V.N.K.); nek6@tpu.ru (N.E.K.) \\ * Correspondence: rre1@tpu.ru; Tel.: +7-913-880-1428
}

check for updates

Citation: Kudiyarov, V.N.; Elman, R.R.; Kurdyumov, N.E. The Effect of High-Energy Ball Milling Conditions on Microstructure and Hydrogen Desorption Properties of Magnesium Hydride and Single-Walled Carbon Nanotubes. Metals 2021, 11, 1409. https://doi.org/10.3390/ met11091409

Academic Editor: José Valdemar Fernandes

Received: 28 July 2021

Accepted: 3 September 2021

Published: 6 September 2021

Publisher's Note: MDPI stays neutral with regard to jurisdictional claims in published maps and institutional affiliations.

Copyright: (c) 2021 by the authors. Licensee MDPI, Basel, Switzerland. This article is an open access article distributed under the terms and conditions of the Creative Commons Attribution (CC BY) license (https:/ / creativecommons.org/licenses/by/ $4.0 /)$.
Abstract: Magnesium hydride is considered to be one of the most promising hydrogen storage materials, although it nevertheless has some problems, such as the high value of the activation energy of hydrogen desorption. To solve this problem, some scientists have proposed adding nanocarbon materials, in particular carbon nanotubes, to magnesium hydride. Currently, a detailed understanding of the mechanisms of obtaining composites based on magnesium hydride and carbon nanotubes is lacking, as is our understanding of the effect of nanocarbon additives on the activation energy and temperature of hydrogen desorption depending on the parameters of the composite synthesis. In addition, the data obtained at various values of milling parameters are very different, and in some works the effect of carbon nanomaterials on the hydrogen properties of magnesium hydride was not confirmed at all. Thus, it is important to determine the effect of nanocarbon additives on the properties of hydrogen storage of magnesium hydride under various milling parameters. This work is devoted to the study of the effect of nanocarbon additives on magnesium hydride and the determination of the dependences of the hydrogen desorption temperature and activation energy on the synthesis parameters. Composite powders containing $\mathrm{MgH}_{2}$ with $5 \mathrm{wt}$.\% single-walled carbon nanotubes (SWCNT) were prepared using a planetary ball mill. The milling was carried out at various milling speeds, namely 300,660, and $900 \mathrm{rpm}$. Results suggested that the structure of the nanotubes is preserved with prolonged grinding of magnesium hydride and SWCNT in a ball mill for $180 \mathrm{~min}$ at a relatively low grinding speed of $300 \mathrm{rpm}$. The composite obtained with these parameters has the lowest temperature of hydrogen desorption and an activation energy of $\mathrm{H}_{2}$ desorption of $162 \pm 1 \mathrm{~kJ} / \mathrm{mol} \mathrm{H}_{2}$, which is $15 \%$ lower than that of the magnesium hydride $\mathrm{MgH}_{2}$ $\left(189 \pm 1 \mathrm{~kJ} / \mathrm{mol} \mathrm{H}_{2}\right)$.

Keywords: carbon nanotubes; magnesium hydride; hydrogen storage materials; hydrogenation; composite materials; hydrogen desorption; temperature of desorption; activation energy of desorption

\section{Introduction}

The development of promising materials for hydrogen storage is one of the most important challenges for the improvement of hydrogen economy [1-3]. One such effective and attractive hydrogen storage method is storage in metal hydrides. Hydrides have a high bulk density that is comparable to liquid hydrogen, have a wide range of operating pressures and temperatures, and do not require a cryogenic temperature to store hydrogen. Thus, magnesium hydride is highly suitable for storing and transporting hydrogen due to the high mass content of hydrogen, which is about 7.6 wt. $\%$. $\mathrm{H}_{2}$ [4-7]. Nevertheless, the use of magnesium as a reversible hydrogen storage material is problematic because of the high temperature (over $300{ }^{\circ} \mathrm{C}$ ) [8,9] required for hydrogen desorption from magnesium hydride at an acceptable rate. This fact limits the use of magnesium hydride as a material for hydrogen storage. 
To improve the properties of magnesium hydride and other metal hydrides, mechanical methods are used [10-13]. Ball milling is one of the most common methods for removing the oxide layer from the magnesium particle surface leading to particle size reduction. To further improve the storage properties of hydrides, other materials can be added to them, such as transition metals [14,15], oxides [16,17], carbon nanotubes (CNT) [18,19], and another additives.

Carbon nanotubes are considered to be a promising additive material for magnesium hydride. It is assumed that the addition of carbon nanotubes will improve the kinetic properties of magnesium hydride, reduce the sorption/desorption temperatures and the activation energy of hydrogen desorption as a consequence. To date, a significant number of theoretical and experimental results on the sorption and desorption of hydrogen from composites based on magnesium hydride and carbon nanotubes have been published. Several phenomena have been reported that may explain this beneficial effect [20-26].

An improvement in the storage properties of hydrogen in a composite based on magnesium hydride and CNTs was observed by Wu C. Z. et al. [20]. The authors noted that both purified and initial SWCNTs accelerated the kinetics of sorption of hydrogen; however, better kinetics was shown when using initial nanotubes containing metal particles as a catalyst for the growth of CNTs. The temperature of the beginning of desorption of hydrogen was reduced by $60{ }^{\circ} \mathrm{C}$ with the addition of SWCNTs compared to magnesium hydride without any additives. It is assumed that during intense mechanical milling, materials (SWCNTs and carbon nanoparticles) can be incorporated into the $\mathrm{MgH}_{2}$ matrix in order to increase the area phase boundaries, leading to an increase in the rate of hydrogen diffusion. Thus, the authors required $10 \mathrm{~h}$ of milling in order to lower the hydrogen desorption temperature by $60{ }^{\circ} \mathrm{C}$. Lillo-Ro'denas M. A. et al. [27] investigated the effect of various carbon materials on the decomposition of magnesium hydride. It was found that the best hydrogenation kinetics and the lowest hydrogen desorption temperature were achieved with the addition of carbon nanofibers and MWCNTs (in the presence of $\mathrm{Ni}$ and Fe impurities). The decomposition temperature of magnesium hydride in the $\mathrm{MgH}_{2}-5$ wt.\% MWCNT composite was slightly lower when the composite was milled at $300 \mathrm{rpm}$ for $2 \mathrm{~h}\left(341^{\circ} \mathrm{C}\right)$ and $1 \mathrm{~h}\left(342^{\circ} \mathrm{C}\right)$ compared to when the composite was milled for $15 \mathrm{~min}\left(346^{\circ} \mathrm{C}\right)$, and the authors concluded that increasing milling time beyond $2 \mathrm{~h}$ did not produce further benefit to $\mathrm{MgH}_{2}$ decomposition. An improvement in the kinetics of the sorption reaction was observed by Lototskyy M. et al. [21]. The authors studied the sorption properties of a composite based on magnesium and carbon materials and obtained by ball milling in a hydrogen atmosphere at $500 \mathrm{rpm}$. The authors argue that destruction of the tubular structures of the multiwall carbon nanotubes (MWCNT), which were mostly resistant to the milling, required only $2 \mathrm{~h}$ of milling at 370-510 rpm [22]. It was found that the addition of $5 \mathrm{wt}$.\% MWCNTs led to a significant improvement in the kinetics of hydrogen sorption. The hydrogen desorption temperature of the $\mathrm{MgH}_{2}-5 \% \mathrm{MWCNT}$ composite prepared for $1.5 \mathrm{~h}$ was $43^{\circ} \mathrm{C}$ lower compared to pure magnesium hydride and about $6{ }^{\circ} \mathrm{C}$ higher compared to ball-milled magnesium hydride. The authors associated the results obtained in their work with the effects arising from the mutual grinding of $\mathrm{Mg}$ and CNTs. Since MWCNTs are known to be very hard in the axial direction, the "scratching" effect becomes pronounced, allowing the exposed "fresh" surface to react with hydrogen. Campos R. B. V. et al. [23] studied the effect of carbon nanotubes on the properties of magnesium hydride. The mixture of magnesium hydride and CNTs was milled for $20 \mathrm{~min}$, which is considered sufficient to form a composite. The decomposition temperature of the hydride in the sample was reduced by $52{ }^{\circ} \mathrm{C}$ in comparison with milled magnesium hydride. The authors suggest that carbon nanotubes can be embedded into $\mathrm{Mg} / \mathrm{MgH}_{2}$ particles, as acting as hydrogen diffusion pathways.

However, the problem of determining the influence of such parameters as the milling speed and milling time on the temperature of hydrogen desorption remains not completely clear and sometimes controversial. As can be seen from the works presented above, there are differing data on the milling time required to form a composite with the best desorption 
properties. It is also necessary to understand whether the preserved structure of the nanotubes has a greater effect than the destroyed. In addition, it is worth noting that there are also works showing insignificant or even negative influence on the desorption properties of $\mathrm{MgH}_{2}$. Huang Z. G. et al. [28] investigated composite $\mathrm{MgH}_{2}-\mathrm{x}$, where $\mathrm{x}$ is MWCNT, carbon black and graphite. The authors synthesized composites using a magnetic ball mill in a hydrogen atmosphere for $48 \mathrm{~h}$. Compared with the initial magnesium hydride, the hydrogen desorption temperature decreased insignificantly, and the difference was about $20^{\circ} \mathrm{C}$. Additionally, no significant difference in catalytic effects was found between MCNTs, graphite and carbon black. Cai W. et al. [29] found that the addition of carbon nanotubes prevents the nucleation of the metal from the hydride as a result of nanoconfinement, reducing the efficiency of the desorption kinetics.

Thus, it is still necessary to consider the dependences of the influence of the synthesis parameters on the hydrogen desorption properties of $\mathrm{MgH}_{2}-\mathrm{CNTs}$ composites. In this study, we prepared and investigated a composite system that was obtained by mechanical milling of $\mathrm{MgH}_{2}$ with single-walled carbon nanotubes. Scanning electron microscopy (SEM) and energy dispersive X-ray (EDX) analysis were used to determine the fact of the structural integrity of the CNTs and obtaining $\mathrm{MgH}_{2}-5 \mathrm{wt}$ \% SWCNT composites. The aim of this study is to further clarify the effect of carbon materials on the properties of $\mathrm{MgH}_{2}$ dehydrogenation. The particular attention was paid to the determination of the temperature and activation energy of hydrogen desorption. The results of this work can be used to conduct further research on the study of hydrogen desorption processes in $\mathrm{MgH}_{2}-\mathrm{CNT}$ composites, as well as to study the effect of nanocarbon additives on the properties of magnesium hydride.

\section{Materials and Methods}

All sample preparation procedures, including unpacking, loading into the grinding jars, distributing the powder into various containers, and placing the samples in a vacuum desiccator for further research, were carried out in a glove box in atmosphere of purified argon (99.999\%), maintaining the water vapor and oxygen levels below 1 ppm.

To obtain the composite, MPF-4 magnesium powder of high purity $99.2 \%$ with a particle size of 50-300 $\mu \mathrm{m}$ was used. Then the magnesium powder was milled and hydrogenated. Single-walled carbon nanotubes (nanotube content $\geq 75 \mathrm{wt}^{\mathrm{o}} \%$ ) Tuball ${ }^{\mathrm{TM}}$ by OCSiAl company with an outer diameter of $1.6 \pm 0.4 \mathrm{~nm}$ and a content of metallic impurities (Fe) less than $12 \mathrm{wt}$ \% were used as an additive material.

Magnesium hydride was obtained by hydrogenation from the gas phase using a Sievert apparatus automated Gas Reaction Controller [30] from the Advanced Material Corporation. Before hydrogenation, magnesium powder was mechanically activated in an AGO-2 planetary ball mill for $1 \mathrm{~h}$ in an argon atmosphere. The ball-to-powder weight ratio was 20:1. The process of gas-phase hydrogenation was carried out at a temperature of $400{ }^{\circ} \mathrm{C}$ and a pressure of $30 \mathrm{~atm} \mathrm{H}_{2}$. Upon reaching these values of temperature and pressure in the chamber, the powder sample was kept in the chamber for $5 \mathrm{~h}$. The conversion of magnesium to hydride was over 90 vol.\%. The spectra of thermally stimulated desorption of magnesium hydride and composites were also obtained on automated complex Gas Reaction Controller with an integrated RGA100 quadrupole mass spectrometer from Stanford Research Systems. For the measurements, the specimens placed in the vacuum chamber were heated to $550{ }^{\circ} \mathrm{C}$ at a constant rate of 4,6 , and $8{ }^{\circ} \mathrm{C} / \mathrm{min}$. The binding energy of hydrogen atoms with surrounding lattice atoms was determined by the Kissinger method [31]. Structural phase analysis was performed on a Shimadzu XRD7000 diffractometer [32], morphology was determined using a TESCAN VEGA 3 SBU scanning electron microscope, and thermogravimetric analysis (TGA)/differential scanning calorimetry (DSC) was performed on an STA 449 F3 Jupiter analyzer. The synthesis of $\mathrm{MgH}_{2}-\mathrm{SWCNT}$ composites was carried out using an AGO-2 planetary mill in an argon atmosphere. The amount of added single-wall carbon nanotubes was $5 \mathrm{wt}$.\%. 


\section{Results and Discussion}

We wanted to determine how the milling parameters affect the integrity of the nanotubes structure. Then it was necessary to consider the influence of the parameters on the hydrogen desorption properties of $\mathrm{MgH}_{2}-5 \mathrm{wt} . \%$ SWCNT composites obtained in the process of milling.

The speed of the grinding jars and the duration of the ball milling were chosen as the variable parameters for obtaining the composite, since these parameters are the main factors that determine the properties of the obtained composite. SEM images of $\mathrm{MgH}_{2}$ $5 \mathrm{wt} . \%$ SWCNT composites, obtained after $60 \mathrm{~min}$ of milling at speeds of $660 \mathrm{rpm}$ and $900 \mathrm{rpm}$ are shown in Figure 1a,b, respectively.
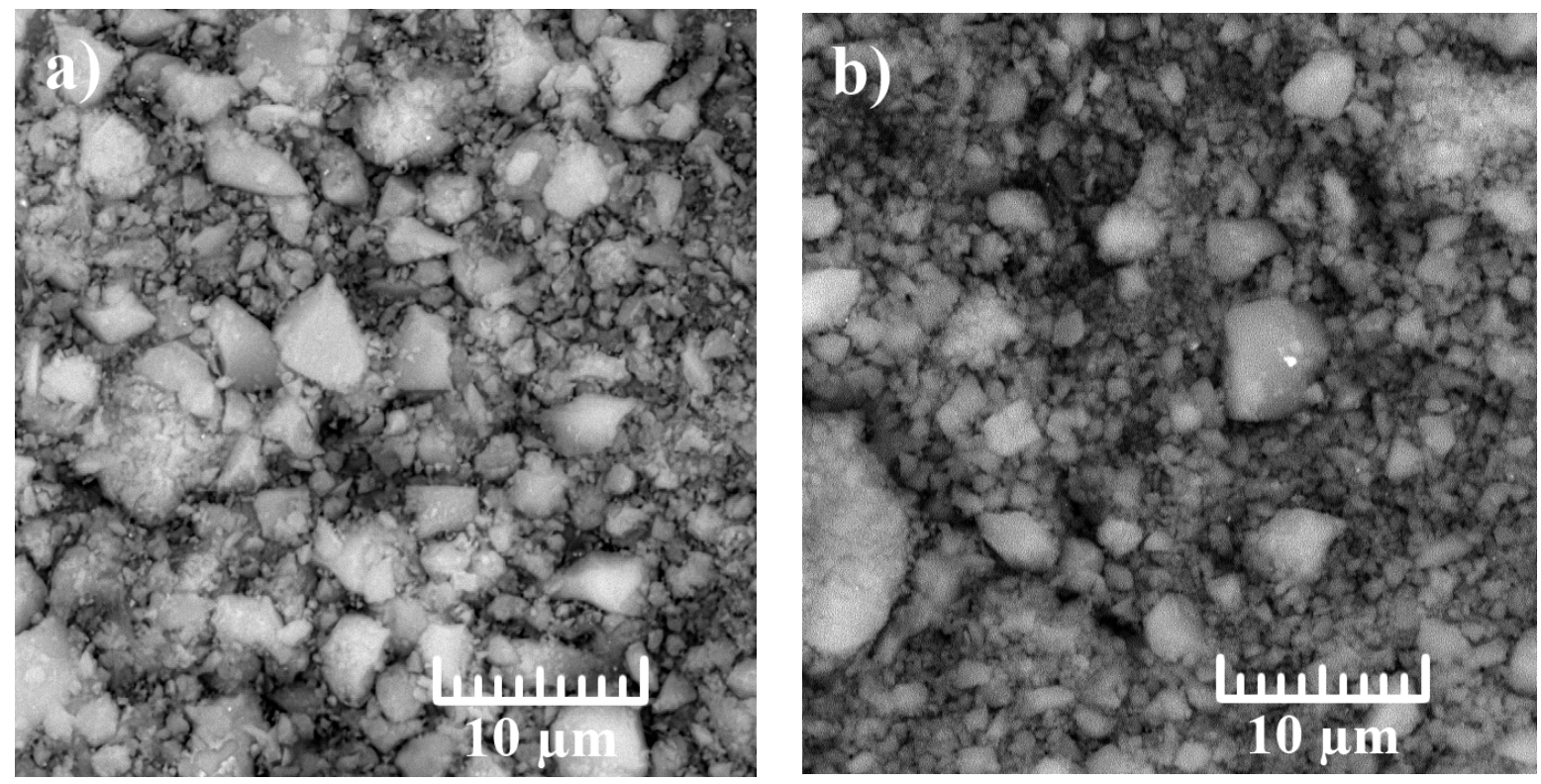

Figure 1. SEM images of $\mathrm{MgH}_{2}-5 \mathrm{wt} . \%$ SWCNT, obtained after $60 \mathrm{~min}$ of ball milling at speeds of $660 \mathrm{rpm}(\mathbf{a})$ and $900 \mathrm{rpm}(\mathbf{b})$.

Figure 1 shows that CNT structures in the obtained $\mathrm{MgH}_{2}-5 \mathrm{wt} . \%$ SWCNT composite could not be clearly observed by scanning electron microscopy, which indicates their destruction at the selected milling speeds, which correlates with the works of Lototskyy M. et al. [21], Popilevsky L. et al. [33] and Amirkhiz B.S. et al. [34]. The samples contain a large number of particles smaller than $2 \mu \mathrm{m}$ and several large particles over $10 \mu \mathrm{m}$. In addition, some particles become smoother. Thus, it has been shown that high rotation speed of the grinding jars when milling $\mathrm{MgH}_{2}-5 \mathrm{wt} . \%$ SWCNT mixture leads to the transition of particles from an irregular geometric shape to a smoother one. It is assumed that CNTs are distributed over the surface of the particles, preventing their agglomeration. A high rotation speed leads to particle friction and destruction of CNTs, which contributes to the formation of smoother particles $[35,36]$. However, such high rotational speeds can lead to a decrease in the concentration of carbon/graphite particles on the surface of $\mathrm{MgH}_{2}$ particles due to their incorporation into the particles and because of the formation of amorphous carbon [37,38].

Figure 2 represents a SEM image of a $\mathrm{MgH}_{2}-5 \mathrm{wt} . \%$ SWCNT composite obtained by milling for $60 \mathrm{~min}$ and a rotation speed of $300 \mathrm{rpm}$.

As can be seen from the figure presented above, the CNTs are unevenly distributed in the composite, and regions with a large number of nanotube bundles can be observed, while in other regions, the presence of CNTs is not observed. Such an uneven distribution of nanotubes is observed due to the low speed and time of milling. A similar picture with a high concentration of the nanotube network is observed in the work of Campos R. B. V. et al. [23]. However, individual bundles of nanotubes separated from regions with high concentrations of CNTs can also be observed. One such bundle of CNTs is shown in Figure 3. 


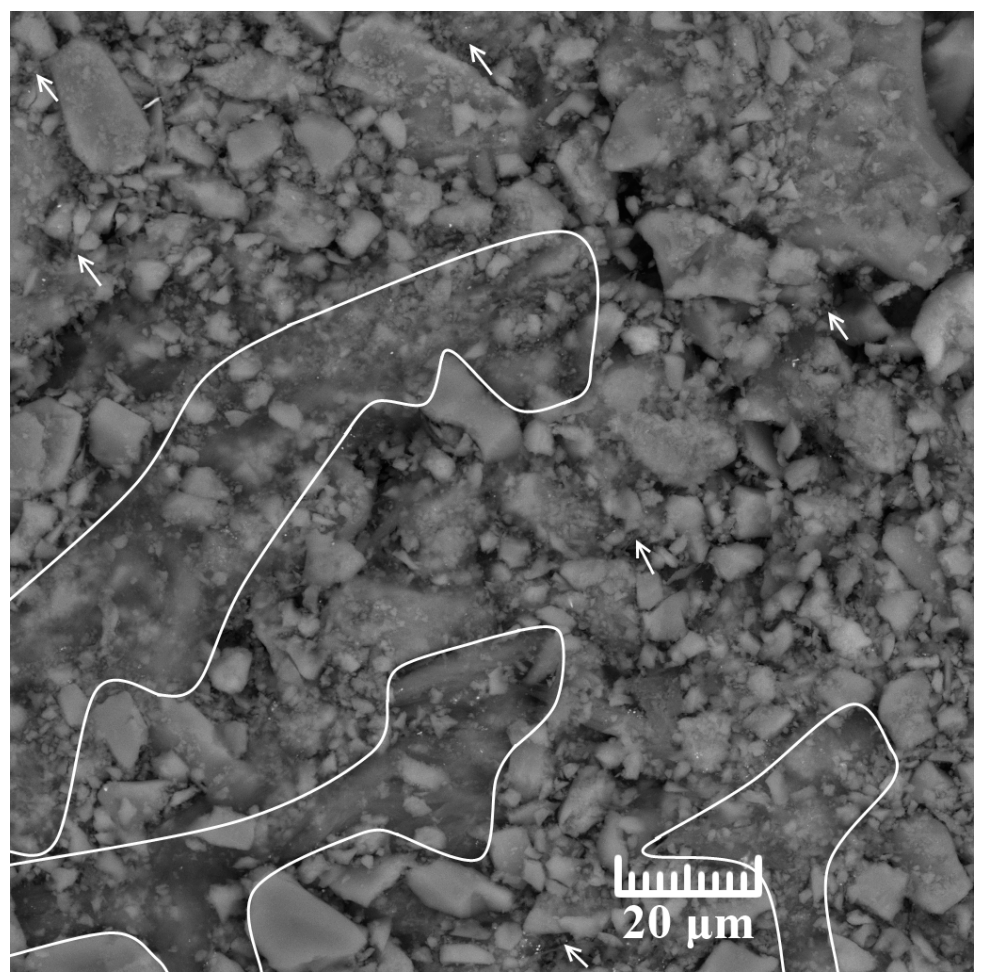

Figure 2. SEM image of the $\mathrm{MgH}_{2}-5 \mathrm{wt}$.\% SWCNT composite obtained after 60 min of ball milling at a speed of $300 \mathrm{rpm}$. Areas marked by white lines indicate areas with a high concentration of nanotube bundles; white arrows mark individual distributed nanotube bundles.

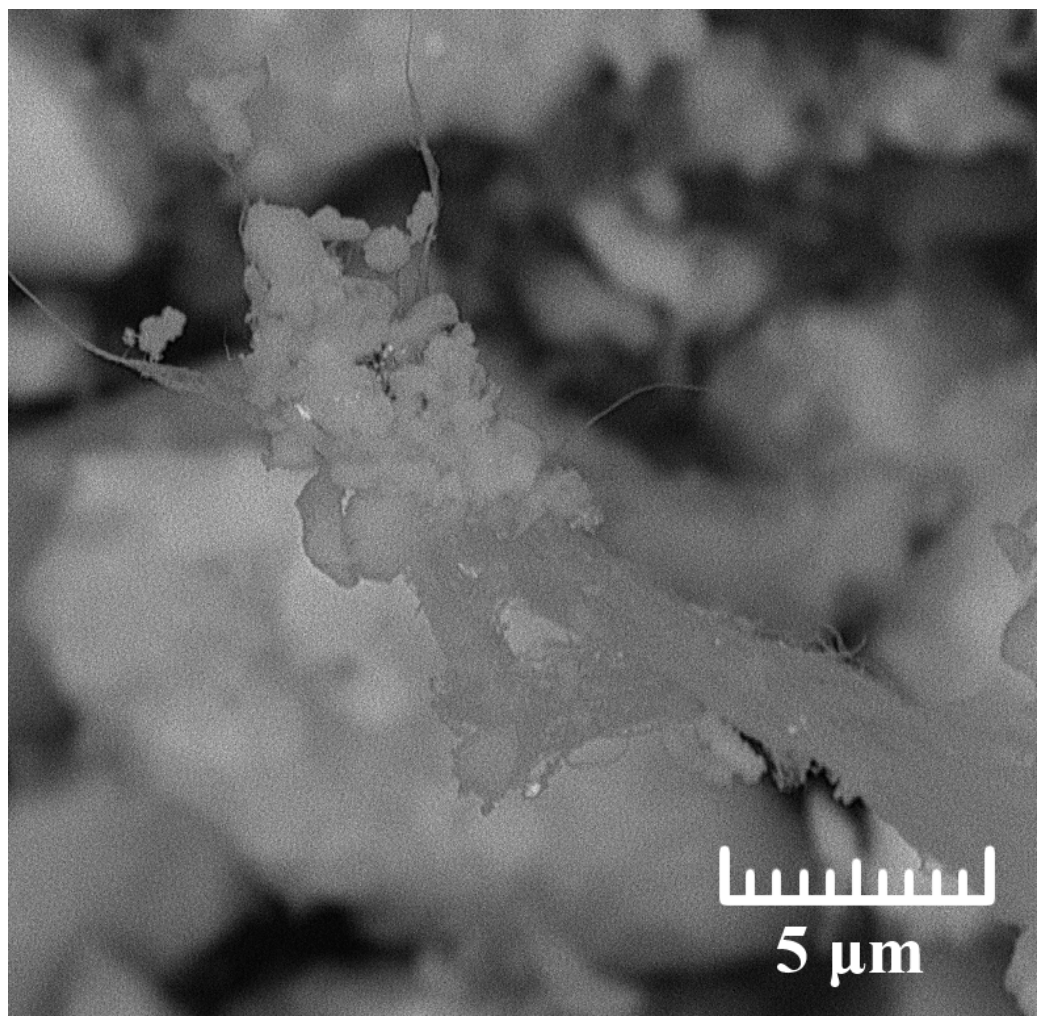

Figure 3. SEM image of an individual bundle of nanotubes with magnesium hydride particles. 
Figure 3 depicts a large number of nanotubes entangled into a bundle, on which there are small (smaller than $2 \mu \mathrm{m}$ ) magnesium particles. It is assumed that most of the CNTs are only in contact with the surface of the particles; however, a certain number of nanotubes can be incorporated into the $\mathrm{MgH}_{2}$ particles. Nevertheless, there is a rather large surface area of CNTs that does not come into contact with magnesium hydride particles due to the low uniformity of distribution of small individual bundles of nanotubes.

Figure 4 shows SEM images of composites obtained by milling at a rotation speed of $300 \mathrm{rpm}$ for $120 \mathrm{~min}$ (Figure 4a,b) and $180 \mathrm{~min}$ (Figure 4c,d).
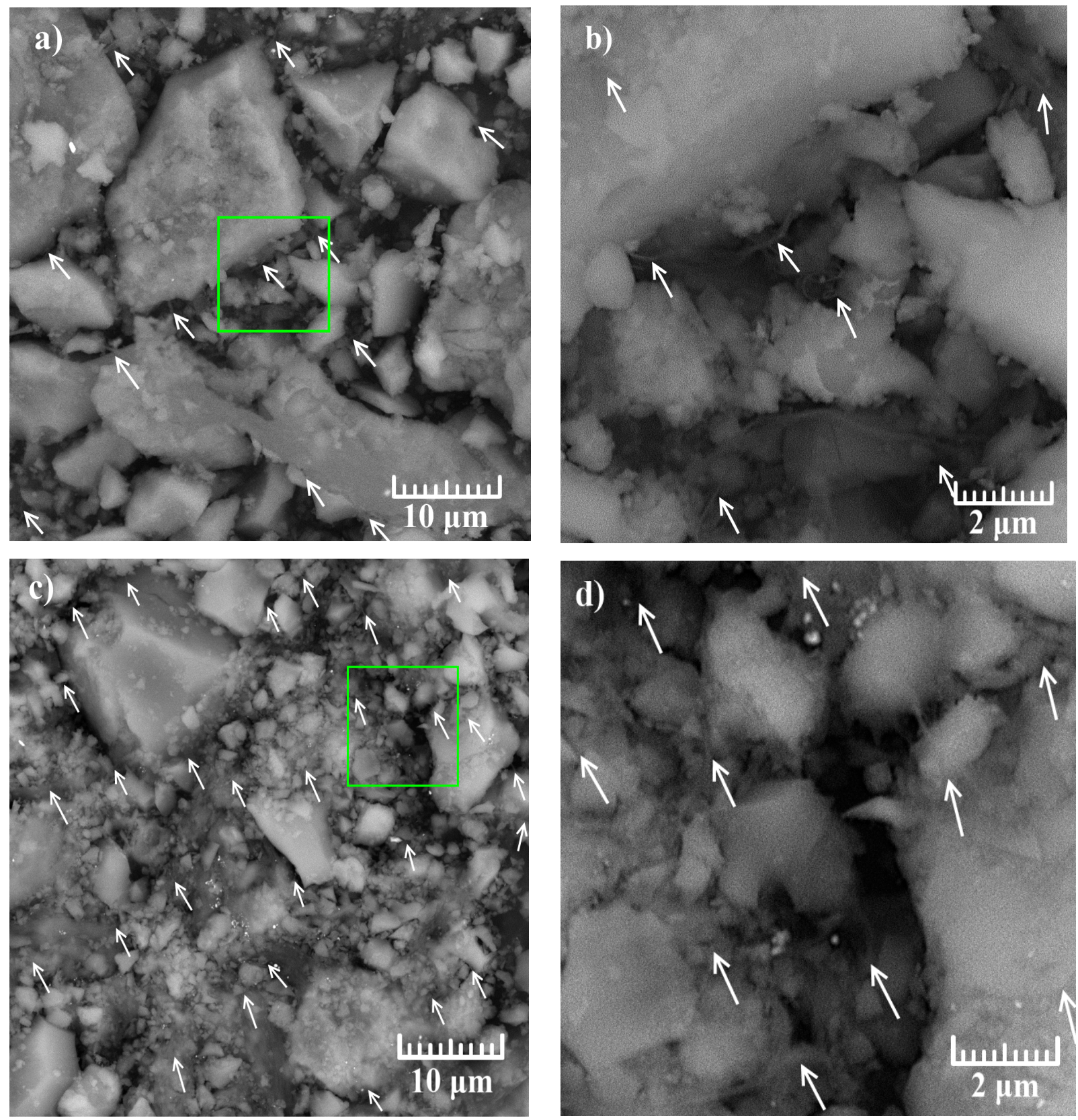

Figure 4. SEM images of the $\mathrm{MgH}_{2}-5$ wt.\% SWCNT composite obtained after $120 \mathrm{~min}(\mathbf{a}, \mathbf{b})$ and $180 \mathrm{~min}$ (c,d) of ball milling at a speed of $300 \mathrm{rpm}$. Rectangular areas marked by green lines indicate the area of the next SEM image; white arrows mark individual distributed nanotube bundles.

It can be seen from the SEM images that an increase in milling time leads to a greater distribution of carbon nanotubes in the composite. Areas with a large number of nanotube bundles are much less common in the composite milled for $120 \mathrm{~min}$, and are not observed 
in the composite milled for $180 \mathrm{~min}$. It should be noted that the particle sizes in the composite obtained at a rotation speed of $300 \mathrm{rpm}$ vary over a wide range from less than $1 \mu \mathrm{m}$ to $24 \mu \mathrm{m}$. Increasing the milling time leads to the formation of particles of smaller size. The average particle size is $6 \pm 2 \mu \mathrm{m}$ for the composite obtained after $120 \mathrm{~min}$ of milling. An increase in the grinding time also significantly affects the size of the nanotube bundles, which become shorter due to destruction and dissolve into individual nanotubes, which are extremely difficult to detect. In addition, the destruction of CNTs leads to the formation of carbon particles, which are then adsorbed onto the surface of the magnesium particles [33,34]. This fact is confirmed by the SEM images and the carbon distribution map shown in Figure 5a,b.
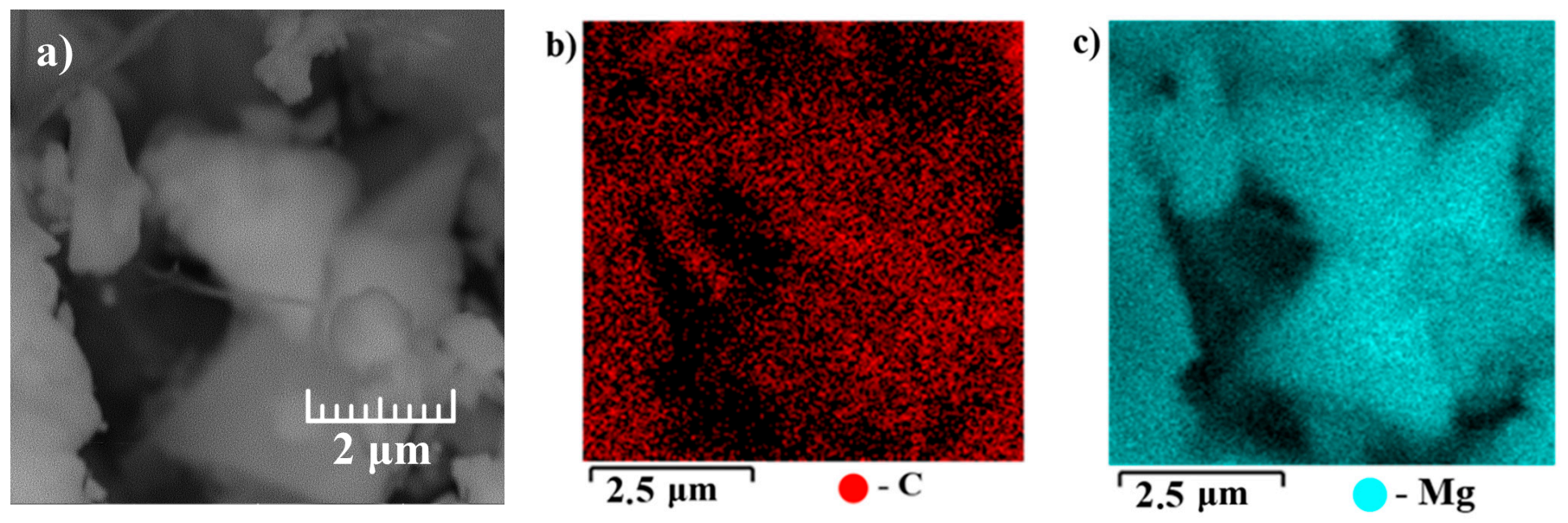

Figure 5. SEM image (a) and map of distribution of carbon (b) and magnesium (c) elements of the $\mathrm{MgH}_{2}-5 \mathrm{wt}$. $\%$ SWCNT composite obtained after $180 \mathrm{~min}$ of ball milling at a speed of $300 \mathrm{rpm}$.

Figure 6 shows the experimental X-ray diffraction pattern of the single-walled carbon nanotubes Tuball ${ }^{\mathrm{TM}}$. As can be seen from this diffractogram, the (002) reflection corresponding to graphite has a very low intensity. However, a peak at $44^{\circ}$ of rather high intensity is observed, which characterizes the presence of metallic impurities. A similar diffraction pattern was obtained in the work of Salamatov I.N. et al. [39], where Tuball ${ }^{\mathrm{TM}}$ nanotubes from OCSiAl company were also studied.

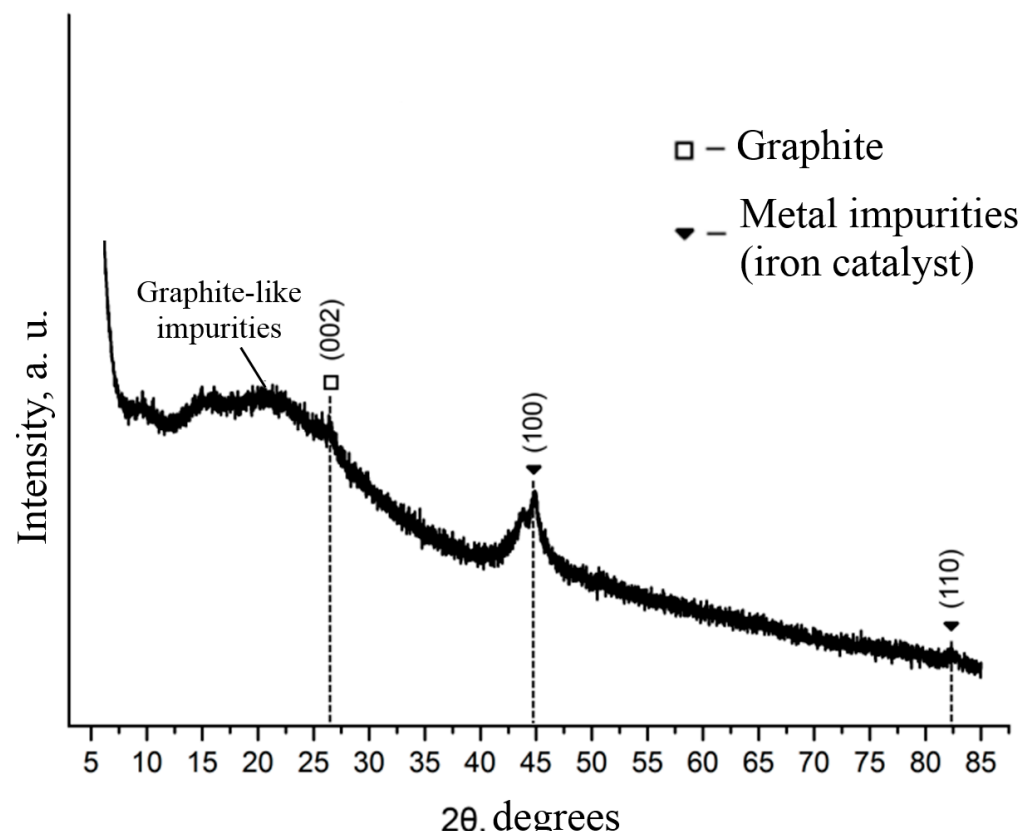

Figure 6. Diffraction pattern of the Tuball ${ }^{\mathrm{TM}}$ single-walled carbon nanotubes. 
Figure 7 represents a comparison of X-ray diffraction patterns for $\mathrm{MgH}_{2}-5$ wt.\% SWCNT composites with respect to speed with a grinding time of $60 \mathrm{~min}$ (Figure 7a) and with milling at a speed of $300 \mathrm{rpm}$ (Figure $7 \mathrm{~b}$ ).
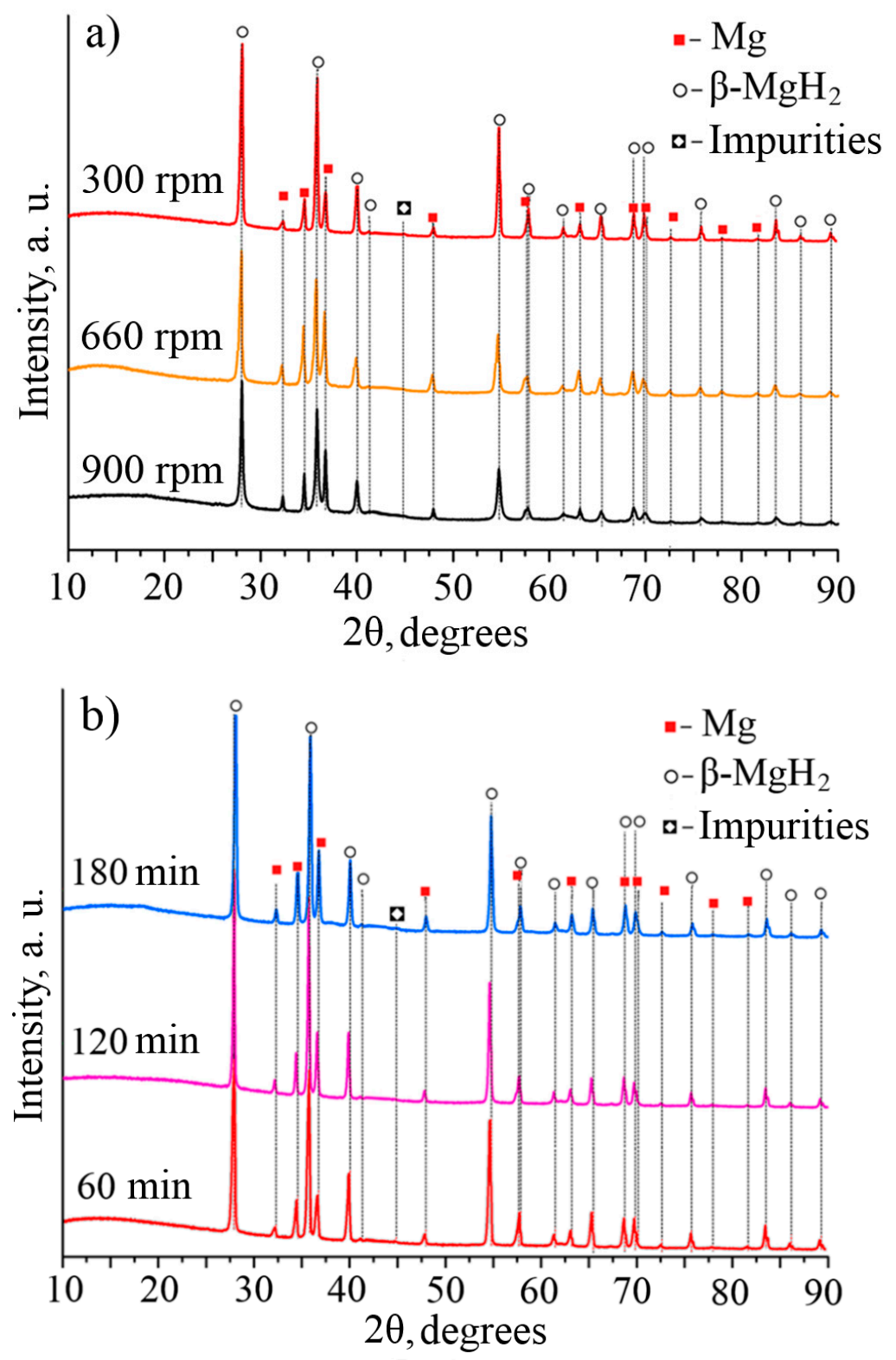

Figure 7. Diffraction patterns of the composite obtained after $60 \mathrm{~min}$ at different speed (a) and obtained at a speed of $300 \mathrm{rpm}$ with different milling durations (b).

Analysis of the diffraction patterns revealed that the phase composition of the composites only slightly changes with increasing speed. Thus, the intensity of diffraction peaks corresponding to the $\beta-\mathrm{MgH}_{2}$ phase slightly decreases and slight peak broadening is observed when the speed is varied from 300 to $900 \mathrm{rpm}$. This can be associated with the reduction in crystallite size as well as the appearance of defects and the increase in lattice strain $[40,41]$. The increase in the milling time at $300 \mathrm{rpm}$ does not affect the phase composition, and the intensity of the diffraction maxima corresponding to magnesium hydride with an increase in milling time from $60 \mathrm{~min}$ to $180 \mathrm{~min}$ does not change. The diffraction peaks corresponding to the carbon structures were not found in all diffraction patterns of the composites due to the low intensity of the peak corresponding to graphite in the diffractogram of the initial Tuball ${ }^{\mathrm{TM}}$ nanotubes (Figure 6). However, weak intensity 
maxima were observed, corresponding to metallic impurities, which may indicate the distribution of CNTs and the formation of a composite.

A comprehensive study using differential scanning calorimetry (DSC) and thermogravimetric (TG) analysis of magnesium hydride and the $\mathrm{MgH}_{2}-5 \mathrm{wt} . \%$ SWCNT composite (at $300 \mathrm{rpm}$ ) were carried out (Figure 8).
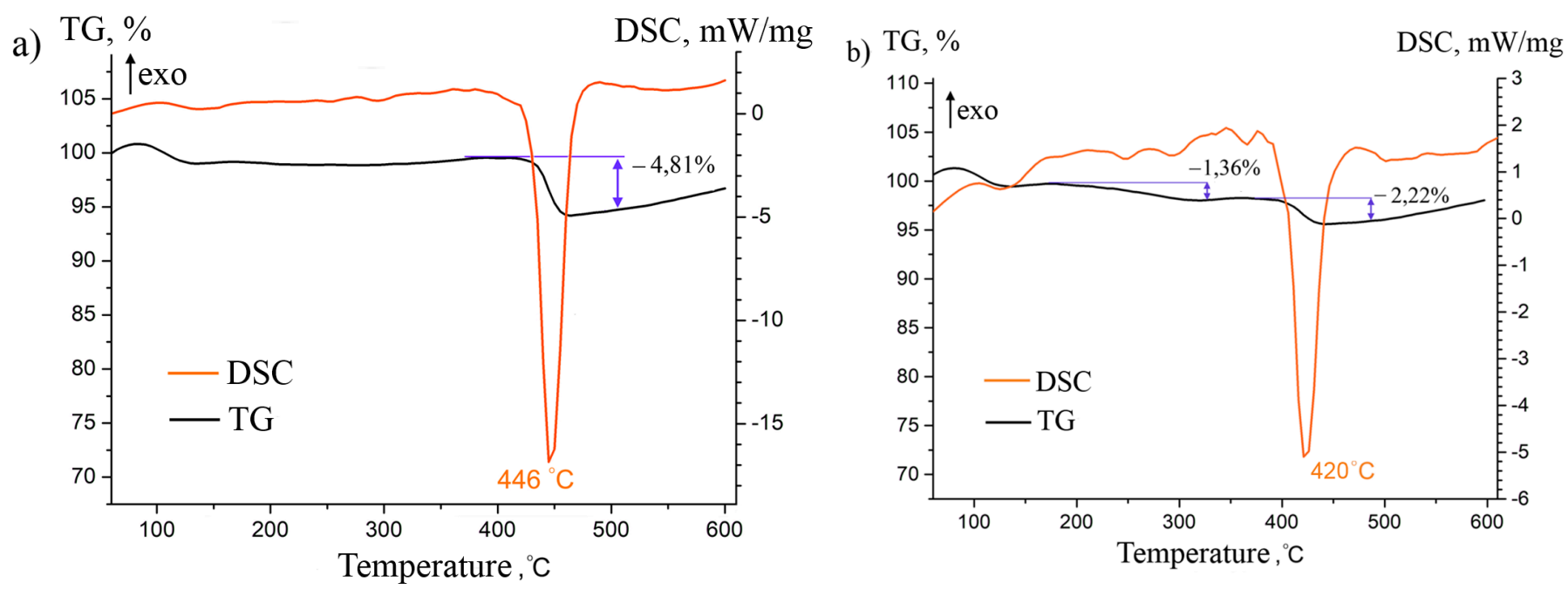

Figure 8. Results of TG and DSC analysis for magnesium hydride (a) and $\mathrm{MgH}_{2}-5$ wt.\% SWCNT composite (b) obtained at a speed of $300 \mathrm{rpm}$.

On the basis of the results of differential scanning calorimetry, one broad endothermic peak can be observed for magnesium hydride, which corresponds to the release of hydrogen from the material. The peak value of the desorption temperature from magnesium hydride is $446{ }^{\circ} \mathrm{C}$ at a heating rate of $6{ }^{\circ} \mathrm{C} / \mathrm{min}$. For the composition $\mathrm{MgH}_{2}-5$ wt. $\%$ SWCNT, obtained by milling at a speed of $300 \mathrm{rpm}$, a lower hydrogen temperature of desorption of $420{ }^{\circ} \mathrm{C}$ can be observed.

The results of TG analysis demonstrate a significant change the mass by $4.81 \%$ of the sample of magnesium hydride in the range corresponding to the temperature of the beginning and the end of hydrogen desorption. As for the $\mathrm{MgH}_{2}-5 \mathrm{wt} . \%$ SWCNT composition obtained at a speed of $300 \mathrm{rpm}$, there is a change in weight by $1.36 \%$ at a relatively low temperature. This fact, similar to the observations of Zlotea et al. [42], can be explained by the presence of ultrafine magnesium particles. These ultra-small particles are characterized by a higher mobility of hydrogen, and can be formed as a result of milling at high speeds and energies. Another area in which a $2.22 \%$ change in mass was recorded was the interval of fast hydrogen desorption, which was also observed during differential scanning calorimetry.

Based on the assumption that maintaining the structure of CNTs can provide a positive effect on the temperature of hydrogen desorption from magnesium hydride, experiments on thermal desorption spectroscopy (TDS) were carried out for all samples of magnesium hydride and $\mathrm{MgH}_{2}-5$ wt.\% SWCNT composites. Hydrogen thermal desorption spectroscopy curves at a heating rate of $6^{\circ} \mathrm{C} / \mathrm{min}$ are shown in Figure 9. 

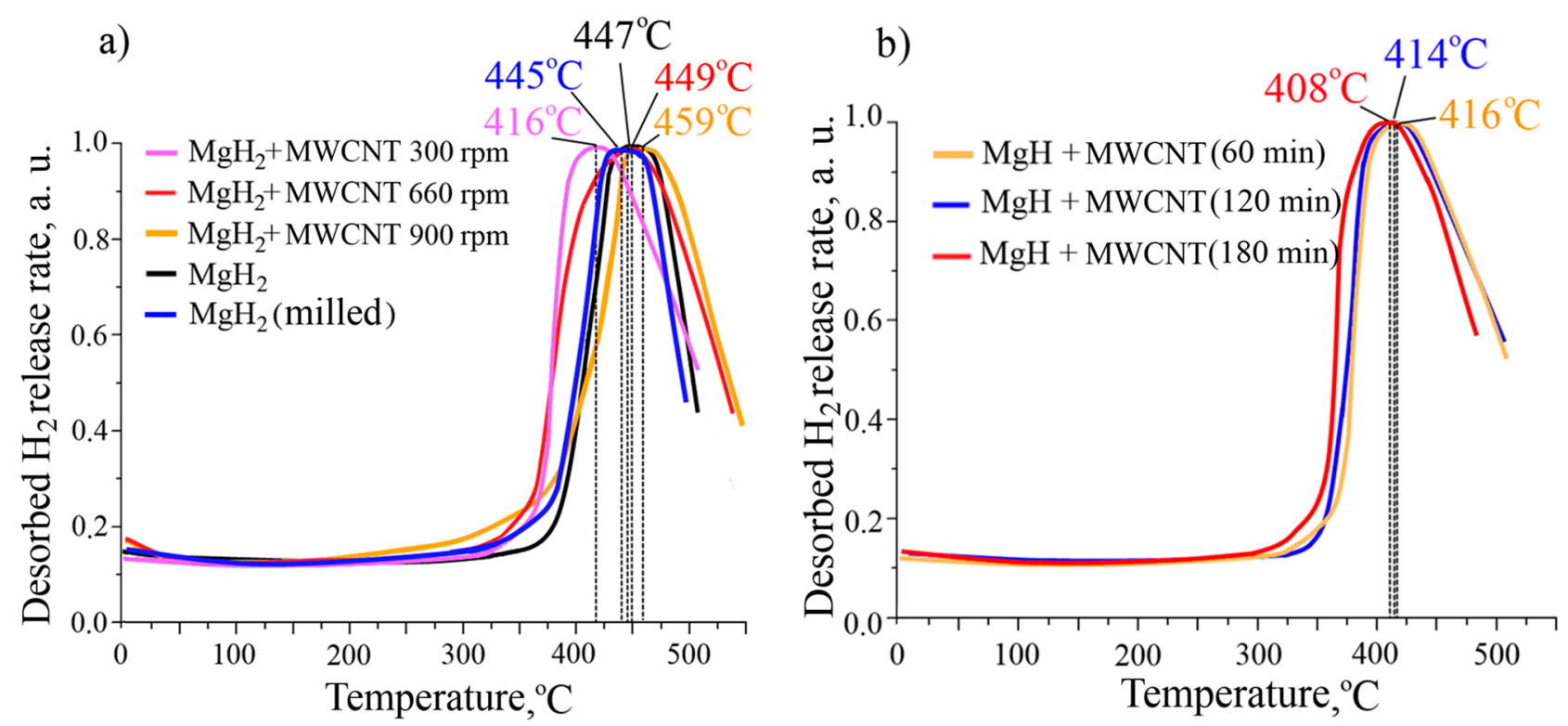

Figure 9. Hydrogen thermal desorption spectroscopy curves for magnesium hydride and $\mathrm{MgH}_{2}-5 \mathrm{wt}$ \% SWCNT composites obtained as a result of milling for $60 \mathrm{~min}$ at a different speeds (a) and at a speed of $300 \mathrm{rpm}$ and different duration of milling (b).

Analyzing the given thermal desorption spectroscopy curves, it can be concluded that the lowest hydrogen temperature of desorption can be observed for the $\mathrm{MgH}_{2}-5 \mathrm{wt} . \%$ SWCNT composite, milled at a speed of $300 \mathrm{rpm}$ under conditions in which the nanotube structure is not completely destroyed. Thus, even milling for a small amount of time (60 min) makes it possible to obtain a composite in which CNTs have a catalytic effect on magnesium hydride. It should be noted that the release of hydrogen begins at a lower temperature for the composites milled at a speed of $900 \mathrm{rpm}, 660 \mathrm{rpm}$ and for the magnesium hydride due to the destruction of coarse particles and the formation of ultrafine particles. The $\mathrm{MgH}_{2}-5 \mathrm{wt} . \%$ SWCNT composition, obtained at a speed of $660 \mathrm{rpm}$, also has a low temperature at the beginning of hydrogen desorption. However, hydrogen desorption with a peak for $\mathrm{MgH}_{2}-5$ wt. $\%$ SWCNT composites obtained at 660 and $900 \mathrm{rpm}$ is observed at a higher temperature. Milled magnesium hydride has a lower temperature both at the beginning of desorption and at peak value relative to non-milled magnesium hydride. However, the difference between peak values is quite insignificant $\left(2{ }^{\circ} \mathrm{C}\right)$. The best results are shown by the composite obtained with a longer milling time $180 \mathrm{~min}$. That fact can be explained by the uniform distribution of nanotubes and metallic impurities, a higher probability of their incorporation into magnesium particles, as well as a decrease in the size of magnesium particles due to the large number of impacts from the balls in the grinding jars. An increase in the grinding time over $180 \mathrm{~min}$ has an insignificant effect on the temperature of hydrogen desorption from the $\mathrm{MgH}_{2}-5 \mathrm{wt} . \%$ SWCNT composite.

To assess the efficiency of hydrogen desorption from the $\mathrm{MgH}_{2}-5 \mathrm{wt} . \%$ SWCNT composite, the hydrogen thermal desorption spectroscopy curves were analyzed using the Kissinger method. To obtain these dependences for magnesium hydride and the $\mathrm{MgH}_{2}-5$ wt.\% SWCNT composite, which showed the lowest desorption temperature (with milling parameters of $300 \mathrm{rpm}$ and $180 \mathrm{~min}$ ), thermal desorption spectroscopy curves were obtained at different heating rates (Figure 10).

Figure 11 represents the graphs of $1 \ln \frac{\beta}{T_{P}^{2}}$ versus $\frac{1000}{T_{p}}$ for magnesium hydride and $\mathrm{MgH}_{2}-5 \mathrm{wt} . \%$ SWCNT composite obtained after $180 \mathrm{~min}$ of ball milling at a speed of $300 \mathrm{rpm}$.

Table 1 presents the data for calculating the activation energy of hydrogen desorption from magnesium hydride and $\mathrm{MgH}_{2}-5 \mathrm{wt} . \%$ SWCNT composite. 

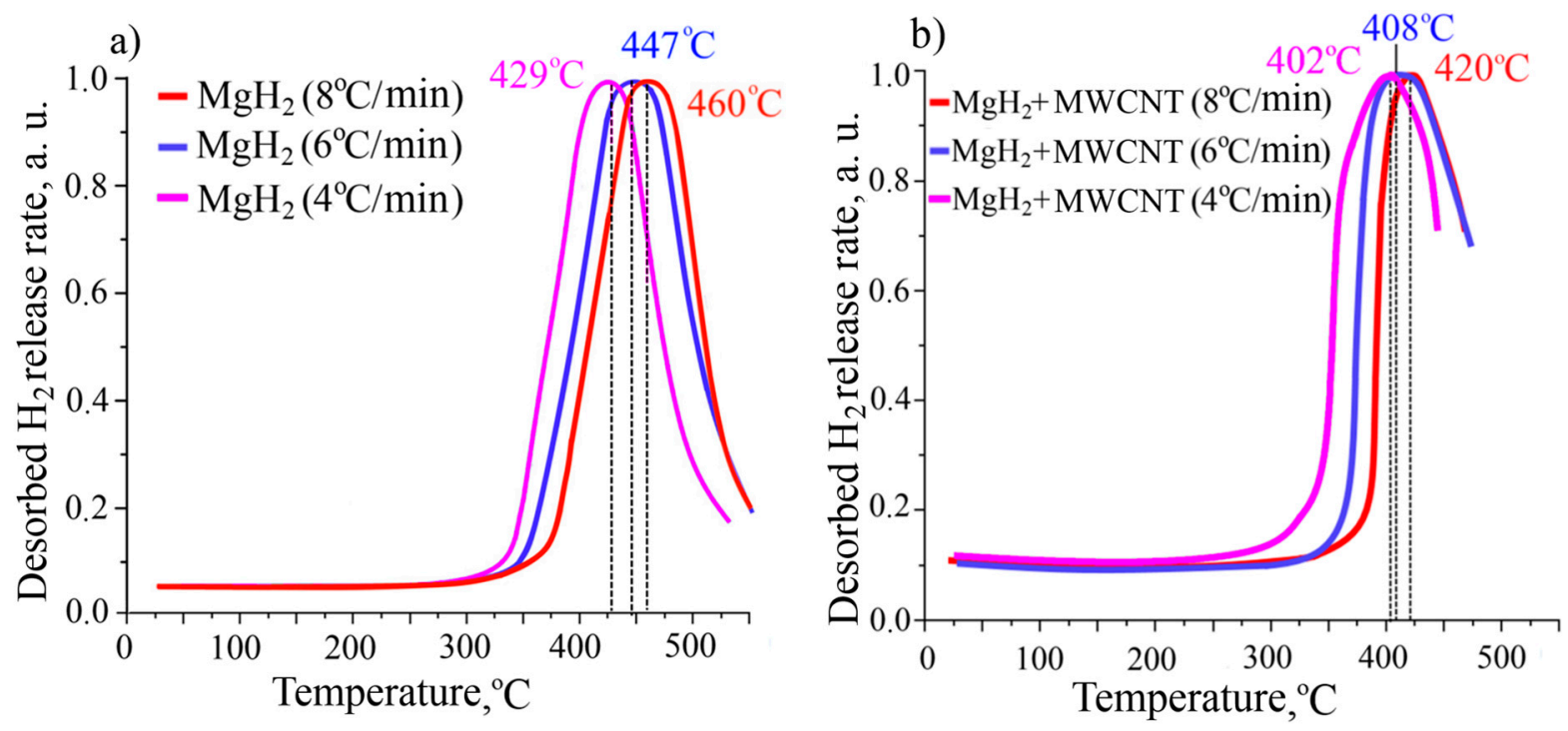

Figure 10. Thermal desorption analysis spectra of magnesium hydride (a) and $\mathrm{MgH}_{2}-5$ wt.\% SWCNT composite (b) obtained after $180 \mathrm{~min}$ of ball milling at a speed of $300 \mathrm{rpm}$.

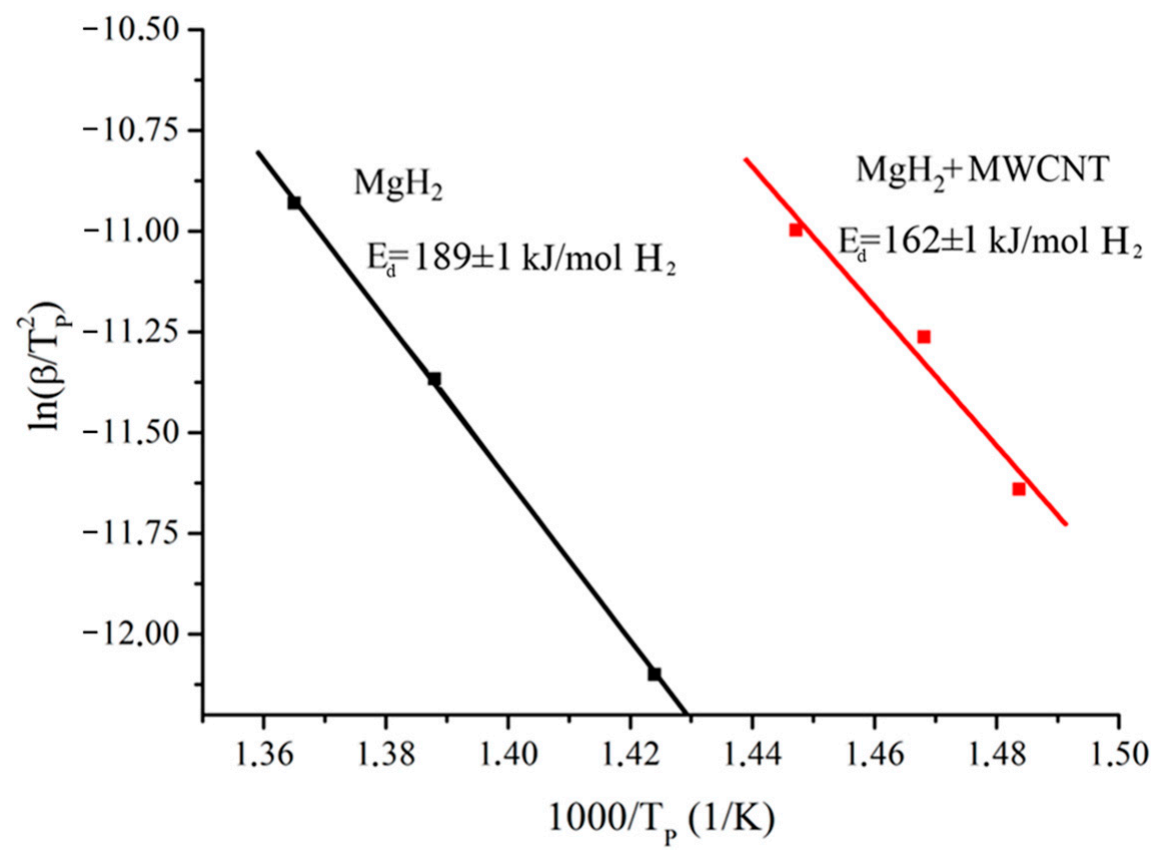

Figure 11. Graphs of $\ln \frac{\beta}{T_{p}^{2}}$ versus $\frac{1000}{T_{p}}$ for $\mathrm{MgH}_{2}$ and $\mathrm{MgH}_{2}-5$ wt.\% SWCNT composite obtained with a milling duration of $180 \mathrm{~min}$ at a speed of $300 \mathrm{rpm}$.

Table 1. Calculation of the activation energy of hydrogen desorption.

\begin{tabular}{cccccc}
\hline № & Sample Name & $\mathbf{T}_{\mathbf{P}}, \mathbf{K}$ & $\boldsymbol{l n} \frac{\beta}{\boldsymbol{T}_{\boldsymbol{P}}^{2}}$ & $\mathbf{E}_{\mathbf{d}}, \mathbf{k J} / \mathbf{m o l}$ & $\begin{array}{c}\mathbf{E}_{\mathbf{d}} \text { (Average), } \\
\mathbf{k J} / \mathbf{m o l}\end{array}$ \\
\hline 1 & & 702 & -12.1 & 188.52 & \\
2 & $\mathrm{MgH}_{2}$ & 720 & -11.4 & 188.96 & 189 \\
3 & & 733 & -10.9 & 189.72 & 162.00 \\
4 & $\mathrm{MgH}_{2}-5 \mathrm{wt} \%$ & 675 & -11.6 & 161.74 & 162 \\
5 & SWCNT (300 rpm, & 681 & -11.3 & 162.86 & \\
6 & 180 min) & 693 & -11.0 & & \\
\hline
\end{tabular}


The table shows that the activation energy of hydrogen desorption for the $\mathrm{MgH}_{2}-$ $5 \mathrm{wt} . \%$ SWCNT composite obtained as a result of milling at a speed of $300 \mathrm{rpm}$ within 180 min was $162 \pm 1 \mathrm{~kJ} / \mathrm{mol} \mathrm{H}_{2}$, which is $15 \%$ less than that of magnesium hydride $\mathrm{MgH}_{2}$ $\left(189 \pm 1 \mathrm{~kJ} / \mathrm{mol} \mathrm{H}_{2}\right)$.

On the basis of the above results, it can be concluded that the addition of single-walled carbon nanotubes to magnesium hydride can reduce the activation energy of desorption and, as a consequence, the hydrogen desorption temperature if the CNT structure is not destroyed, and the CNTs themselves are uniformly distributed in the composite. However, the decrease in the activation energy of desorption in this case is insignificant and is practically within the error limits. A decrease in the activation energy of hydrogen desorption, as well as the temperature of hydrogen desorption, can occur due to the influence of several factors, such as due to the high thermal conductivity of CNTs [43] and their incorporation into magnesium particles, which allows hydrogen atoms to be diffused more easily from the bulk of the material $[37,44]$. It can also be related to the distribution of metal catalysts contained in nanotubes [20]. Thus, a high milling speed turns out to be ineffective, while a relatively long milling time at a relative low speed makes it possible to obtain the catalytic effect of SWCNTs Tuball ${ }^{\mathrm{TM}}$ (although it still remains small). Short milling time at a low speed leads to insufficient distribution of carbon nanotubes in the composite and an unexpressed catalytic effect. Milling only magnesium hydride leads to an earlier release of hydrogen because of the formation of small nanocrystalline $\mathrm{MgH}_{2}$ particles; however, the maximum rate of hydrogen release remains at the same level as that of unmilled $\mathrm{MgH}_{2}$. According to the results of this study, it was also found that nanotubes Tuball $^{\mathrm{TM}}$ do not make a significant contribution to X-ray diffraction patterns, and the intensity of Bragg peaks corresponding to metallic impurities remains very low.

\section{Summary}

Based on the presented results, it can be concluded that the developed technique meets the stated goal and can be applied for further research.

Within the course of the work, it was shown by scanning electron microscopy that an increase in the frequency of revolutions significantly affects the structure of carbon nanotubes, which are already destroyed after ball milling at $660 \mathrm{rpm}$ for $60 \mathrm{~min}$. At the same time, an increase in the milling time from 60 to $180 \mathrm{~min}$ at a relatively low intensity (300 rpm) makes it possible to partially preserve the structure of nanotubes and obtain a composite in which nanotubes are distributed uniformly over its volume. A short milling time leads to an uneven distribution of carbon nanotubes in the volume of the $\mathrm{MgH}_{2}-5 \mathrm{wt} . \%$ SWCNT composite and an unexpressed catalytic effect. Increases in both the duration and the speed of grinding lead to a decrease in the average $\mathrm{MgH}_{2}$ particle size; however, as the results subsequently showed, that fact did not have a significant effect on the temperature of the hydrogen desorption. Joint milling of $\mathrm{MgH}_{2}$ and SWCNTs led to a slight decrease and broadening of the intensity of the peaks corresponding to magnesium hydride due to a decrease in the crystallite size, the appearance of defects and strains of the crystal lattice. All diffraction patterns of composites exhibit low-intensity peaks corresponding to metal impurities contained in nanotubes as catalyst or their growth. The best results in terms of the activation energy and the temperature of the hydrogen desorption were shown by the composite milled for $180 \mathrm{~min}$ at $300 \mathrm{rpm}$. The temperature of the $\mathrm{H}_{2}$ desorption from this composite is $408^{\circ} \mathrm{C}$, which is $39^{\circ} \mathrm{C}$ less than the temperature of the hydrogen desorption from magnesium hydride $\left(447^{\circ} \mathrm{C}\right)$. The activation energy of $\mathrm{H}_{2}$ desorption from a $\mathrm{MgH}_{2}-$ $5 \mathrm{wt} . \%$ SWCNT composite ( $180 \mathrm{~min}, 300 \mathrm{rpm}$ ) is $162 \pm 1 \mathrm{~kJ} / \mathrm{mol}$, which is $15 \%$ lower than the activation energy of $\mathrm{H}_{2}$ desorption from magnesium hydride $(189 \pm 1 \mathrm{~kJ} / \mathrm{mol})$. The mechanism of the catalytic effect can be associated with several factors and phenomena, such as incorporation of CNTs into magnesium particles, high thermal conductivity of CNTs, or influence of catalytic additives used for the growth of nanotubes.

Despite the fact that the addition of CNTs to magnesium hydride in accordance with the parameters indicated above shows a catalytic effect, this effect remains weakly 
pronounced. Thus, it is recommended to use carbon nanotubes as an additive to magnesium hydride only with the other catalytic additives because of the minimal decrease in the temperature and activation energy of hydrogen desorption.

Author Contributions: V.N.K. carried out the organization of the workflow and preparation of the article, N.E.K. performed the XRD tests, R.R.E. conducted the experiments on hydrogenation, R.R.E. and N.E.K. performed the analysis of the results. All authors have read and agreed to the published version of the manuscript.

Funding: The research was funded by the Governmental program "Science", research project No. FSWW-2020-0017.

Institutional Review Board Statement: Not applicable.

Informed Consent Statement: Not applicable.

Data Availability Statement: Not applicable.

Acknowledgments: This research was supported by TPU development program.

Conflicts of Interest: The authors declare no conflict of interest.

\section{References}

1. Ortiz, A.L.; Zaragoza, M.J.M.; Collins-Martínez, V. Hydrogen production research in Mexico: A review. Int. J. Hydrogen Energy 2016, 41, 23363-23379. [CrossRef]

2. Armaroli, N.; Balzani, V. The hydrogen issue. ChemSusChem 2011, 4, 21-36. [CrossRef] [PubMed]

3. Rivard, E.; Trudeau, M.; Zaghib, K. Hydrogen storage for mobility: A review. Materials 2019, 12, 1973. [CrossRef]

4. Zhou, C.; Zhang, J.; Bowman, R.C., Jr.; Fang, Z.Z. Roles of Ti-Based Catalysts on Magnesium Hydride and Its Hydrogen Storage Properties. Inorganics 2021, 9, 36. [CrossRef]

5. Wang, Y.; Wang, Y. Recent advances in additive-enhanced magnesium hydride for hydrogen storage. Prog. Nat. Sci. Mater. Int. 2017, 27, 41-49. [CrossRef]

6. Sabitu, S.T.; Goudy, A.J. Dehydrogenation kinetics and modeling studies of $\mathrm{MgH}_{2}$ enhanced by transition metal oxide catalysts using constant pressure thermodynamic driving forces. Metals 2012, 2, 219-228. [CrossRef]

7. Lider, A.; Kudiiarov, V.; Kashkarov, E.; Syrtanov, M.; Murashkina, T.; Lomygin, A.; Sakvin, I.; Karpov, D.; Ivanov, A. Hydrogen Accumulation and Distribution in Titanium Coatings at Gas-Phase Hydrogenation. Metals 2020, 10, 880. [CrossRef]

8. Crivello, J.C.; Denys, R.V.; Dornheim, M.; Felderhoff, M.; Grant, D.M.; Huot, J.; Jensen, T.R.; de Jongh, P.; Latroche, M.; Walker, G.S.; et al. Mg-based compounds for hydrogen and energy storage. Appl. Phys. A 2016, 122, 17. [CrossRef]

9. Zhu, M.; Lu, Y.; Ouyang, L.; Wang, H. Thermodynamic Tuning of Mg-Based Hydrogen Storage Alloys: A Review. Materials 2013, 6, 4654-4674. [CrossRef]

10. Da Silva Dupim, I.; Ferreira Santos, S.; Huot, J. Effect of Cold Rolling on the Hydrogen Desorption Behavior of Binary Metal Hydride Powders under Microwave Irradiation. Metals 2015, 5, 2021-2033. [CrossRef]

11. Huot, J.; Tousignant, M. Effect of cold rolling on metal hydrides. Mater. Trans. 2019, 60, 1571-1576. [CrossRef]

12. Lyu, J.; Lider, A.; Kudiiarov, V. Using ball milling for modification of the hydrogenation/dehydrogenation process in magnesiumbased hydrogen storage materials: An overview. Metals 2019, 9, 768. [CrossRef]

13. Song, M.Y.; Choi, E.; Kwak, Y.J. Nickel, Graphene, and Yttria-Stabilized Zirconia (YSZ)-Added Mg by Grinding in Hydrogen Atmosphere for Hydrogen Storage. Metals 2019, 9, 1347. [CrossRef]

14. Hanada, N.; Ichikawa, T.; Fujii, H. Catalytic effect of nanoparticle 3d-transition metals on hydrogen storage properties in magnesium hydride $\mathrm{MgH}_{2}$ prepared by mechanical milling. J. Phys. Chem. B 2005, 109, 7188-7194. [CrossRef]

15. Shelyapina, M.G.; Fruchart, D. Role of transition elements in stability of magnesium hydride: A review of theoretical studies. Solid State Phenom. 2011, 170, 227-231. [CrossRef]

16. Patah, A.; Takasaki, A.; Szmyd, J.S. Synergetic effect of oxides on hydrogen reaction kinetics of magnesium hydride. Mater. Sci. Forum 2007, 561, 1605-1608. [CrossRef]

17. Jung, K.S.; Lee, E.Y.; Lee, K.S. Catalytic effects of metal oxide on hydrogen absorption of magnesium metal hydride. J. Alloy. Compd. 2006, 421, 179-184. [CrossRef]

18. Pandyan, R.K.; Seenithurai, S.; Kumar, S.V.; Mahendran, M. Magnesium Hydride Doped on Single-Walled Carbon Nanotubes for Hydrogen Adsorption. Fuller. Nanotub. Carbon Nanostruct. 2015, 23, 175-180. [CrossRef]

19. Wu, C.Z.; Wang, P.; Yao, X.; Liu, C.; Chen, D.M.; Lu, G.Q.; Cheng, H.M. Effect of carbon/noncarbon addition on hydrogen storage behaviors of magnesium hydride. J. Alloy. Compd. 2006, 414, 259-264. [CrossRef]

20. Wu, C.; Wang, P.; Yao, X.; Liu, C.; Chen, D.; Lu, G.Q.; Cheng, H. Effects of SWNT and metallic catalyst on hydrogen absorption/desorption performance of $\mathrm{MgH}_{2}$. J. Phys. Chem. B 2005, 109, 22217-22221. [CrossRef]

21. Lototskyy, M.; Sibanyoni, J.M.; Denys, R.V.; Williams, M.; Pollet, B.G.; Yartys, V.A. Magnesium-carbon hydrogen storage hybrid materials produced by reactive ball milling in hydrogen. Carbon 2013, 57, 146-160. [CrossRef] 
22. Tucho, W.M.; Mauroy, H.; Walmsley, J.C.; Deledda, S.; Holmestad, R.; Hauback, B.C. The effects of ball milling intensity on morphology of multiwall carbon nanotubes. Scr. Mater. 2010, 63, 637-640. [CrossRef]

23. Campos, R.B.V.; Camargo, S.A.D.S.; Brum, M.C.; Santos, D.S.D. Hydrogen uptake enhancement by the use of a magnesium hydride and carbon nanotubes mixture. Mater. Res. 2017, 20, 85-88. [CrossRef]

24. Adelhelm, P.; De Jongh, P.E. The impact of carbon materials on the hydrogen storage properties of light metal hydrides. J. Mater. Chem. 2011, 21, 2417-2427. [CrossRef]

25. Ruse, E.; Pevzner, S.; Bar, I.P.; Nadiv, R.; Skripnyuk, V.M.; Rabkin, E.; Regev, O. Hydrogen storage and spillover kinetics in carbon nanotube-Mg composites. Int. J. Hydrogen Energy 2016, 41, 2814-2819. [CrossRef]

26. Ruse, E.; Buzaglo, M.; Pevzner, S.; Pri-Bar, I.; Skripnyuk, V.M.; Rabkin, E.; Regev, O. Tuning Mg hydriding kinetics with nanocarbons. J. Alloy. Compd. 2017, 725, 616-622. [CrossRef]

27. Lillo-Ródenas, M.A.; Guo, Z.X.; Aguey-Zinsou, K.F.; Cazorla-Amorós, D.; Linares-Solano, A. Effects of different carbon materials on $\mathrm{MgH}_{2}$ decomposition. Carbon 2008, 46, 126-137. [CrossRef]

28. Huang, Z.G.; Guo, Z.P.; Calka, A.; Wexler, D.; Liu, H.K. Effects of carbon black, graphite and carbon nanotube additives on hydrogen storage properties of magnesium. J. Alloy. Compd. 2007, 427, 94-100. [CrossRef]

29. Cai, W.; Zhou, X.; Xia, L.; Jiang, K.; Peng, S.; Long, X.; Liang, J. Positive and negative effects of carbon nanotubes on the hydrogen sorption kinetics of magnesium. J. Phys. Chem. C 2015, 119, 25282-25290. [CrossRef]

30. Kudiiarov, V.N.; Gulidova, L.V.; Pushilina, N.S.; Lider, A.M. Application of automated complex Gas Reaction Controller for hydrogen storage materials investigation. Adv. Mater. Res. 2013, 740, 690-693. [CrossRef]

31. Kissinger, H.E. Reaction Kinetics in Differential Thermal Analysis. Anal. Chem. 1957, 29, 1702-1706. [CrossRef]

32. Syrtanov, M.; Garanin, G.; Kashkarov, E.; Pushilina, N.; Kudiiarov, V.; Murashkina, T. Laboratory X-ray diffraction complex for in situ investigations of structural phase evolution of materials under gaseous atmosphere. Metals 2020, 10, 447. [CrossRef]

33. Popilevsky, L.; Skripnyuk, V.M.; Beregovsky, M.; Sezen, M.; Amouyal, Y.; Rabkin, E. Hydrogen storage and thermal transport properties of pelletized porous $\mathrm{Mg}-2 \mathrm{wt}$ \% multiwall carbon nanotubes and Mg-2 wt.\% graphite composites. Int. J. Hydrogen Energy 2016, 41, 14461-14474. [CrossRef]

34. Amirkhiz, B.S.; Danaie, M.; Mitlin, D. The influence of SWCNT-metallic nanoparticle mixtures on the desorption properties of milled $\mathrm{MgH}_{2}$ powders. Nanotechnology 2009, 20, 13. [CrossRef]

35. Albaaji, A.J.; Castle, E.G.; Reece, M.J.; Hall, J.P.; Evans, S.L. Effect of ball-milling time on mechanical and magnetic properties of carbon nanotube reinforced FeCo alloy composites. Mater. Des. 2017, 122, 296-306. [CrossRef]

36. Peng, T.; Chang, I. Mechanical alloying of multi-walled carbon nanotubes reinforced aluminum composite powder. Powder Technol. 2014, 266, 7-15. [CrossRef]

37. Stoyadinova, H.; Zlatanova, Z.; Spassova, M.; Spassov, T.; Baklanov, M. Influence of milling conditions on the hydriding properties of Mg-C nanocomposites. J. Nanomater. 2015, 2015, 6. [CrossRef]

38. Pandey, S.K.; Singh, R.K.; Srivastava, O.N. Investigations on hydrogenation behaviour of CNT admixed Mg 2 Ni. Int. J. Hydrogen Energy 2009, 34, 9379-9384. [CrossRef]

39. Salamatov, I.N.; Yatsenko, D.A.; Khasin, A.A. Determination of the Diameter Distribution Function of Single-Wall Carbon Nanotubes by the X-Ray Diffraction Data. J. Struct. Chem. 2019, 60, 2001-2008. [CrossRef]

40. Mahmoud, A.E.; Wasly, H.S.; Doheim, M.A. Studies of crystallite size and lattice strain in $\mathrm{Al}_{-} \mathrm{Al}_{2} \mathrm{O}_{3}$ powders produced by high-energy mechanical milling. J. Eng. Sci. 2014, 42, 1430-1439. [CrossRef]

41. Rahmaninasab, M.A.; Raygan, S.; Abdizadeh, H.; Pourabdoli, M.; Mirghaderi, S.H. Properties of activated $\mathrm{MgH}_{2}+\mathrm{mischmetal}$ nanostructured composite produced by ball-milling. Mater. Renew. Sustain. Energy 2018, 7, 15. [CrossRef]

42. Zlotea, C.; Oumellal, Y.; Hwang, S.J.; Ghimbeu, C.M.; de Jongh, P.E.; Latroche, M. Ultrasmall $\mathrm{MgH}_{2}$ nanoparticles embedded in an ordered microporous carbon exhibiting rapid hydrogen sorption kinetics. J. Phys. Chem. C 2015, 119, 18091-18098. [CrossRef]

43. Gao, S.; Wang, X.; Liu, H.; He, T.; Wang, Y.; Li, S.; Yan, M. Effects of nano-composites (FeB, FeB/CNTs) on hydrogen storage properties of $\mathrm{MgH}_{2}$. J. Power Sources 2019, 438, 11. [CrossRef]

44. Yahya, M.S.; Ismail, M. Improvement of hydrogen storage properties of $\mathrm{MgH}_{2}$ catalyzed by $\mathrm{K} 2 \mathrm{NbF} 7$ and multiwall carbon nanotube. J. Phys. Chem. C 2018, 122, 11222-11233. [CrossRef] 